\title{
PENGARUH TERPAAN IKLAN TELEVISI DAN PERSEPSI MEREK TERHADAP MINAT BELI (STUDI PADA PRODUK BLACKBERRY DI KALANGAN MAHASISWA FE UNIVERSITAS ISLAM LAMONGAN)
}

\author{
Luluk Nur Azizah \\ Fakultas Ekonomi Prodi Manajemen UNIVERSITAS ISLAM LAMONGAN \\ luluknurazizah_25@ymail.com
}

\begin{abstract}
The purpose of this study is to describe and analyze the positive and significant influence between the exposure of television advertising Blackberry products and brand perception of Blackberry products on the interest of buying Blackberry products on FE Students of Islamic University of Lamongan. The method used is survey method that takes a sample of 76 respondents FE Students of Islamic University of Lamongan. Data analysis techniques used are Product Moment Correlation analysis, multiple correlation, Linear Regression and Multiple Regression with SPSS V.13.0 for windows program. The results of research conducted, it can be seen that there is a positive and significant influence between the exposure of television advertising and brand perception of Blackberry products to the interest in buying Blackberry products. The results of the analysis show that this study supports the S-O-R theory in the Student FE population of Lamongan Islamic University.
\end{abstract}

Keywords: Ad overpayment, brand perception, and buying interest

\begin{abstract}
Abstrak
Tujuan penelitian ini adalah untuk mendeskripsikan dan menganalisis pengaruh yang positif dan signifikan antara terpaan iklan televisi produk Blackberry dan persepsi merek produk Blackberry terhadap minat beli produk Blackberry pada Mahasiswa FE Universitas Islam Lamongan. Metode yang digunakan yaitu metode survai yang mengambil sampel sebanyak 76 responden Mahasiswa FE Universitas Islam Lamongan. Teknik analisis data yang dipakai adalah analisis Korelasi Product Moment, korelasi ganda, Regresi Linear dan Regresi Ganda dengan program SPSS V.13.0 for windows. Hasil penelitian yang dilakukan, dapat diketahui bahwa terdapat pengaruh yang positif dan signifikan antara terpaan iklan televisi dan persepsi merek produk Blackberry terhadap minat beli produk Blackberry. Hasil pengujian hipotesis dengan menggunakan analisis regresi linier dan analisis regresi berganda menunjukkan tidak adanya pengaruh positif dan signifikan antara terpaan iklan televisi terhadap minat beli produk Blackberry. Hasil analisis menunjukkan penelitian ini mendukung teori S-O- R pada populasi Mahasiswa FE Universitas Islam Lamongan.
\end{abstract}

Kata Kunci: Terpaan Iklan, persepsi merek, dan minat beli 


\section{PENDAHULUAN}

Dalam zaman sekarang ini perusahaan dituntut bersaing secara kompetitif (competitive rivalry) dalam hal menciptakan dan mempertahankan konsumen yang loyal (secara lebih spesifik disebut pelanggan), salah satunya adalah melalui perang antar merek. Perusahaan semakin menyadari merek menjadi faktor penting dalam persaingan dan menjadi aset perusahaan yang bernilai. Produk menjelaskan atribut inti sebagai suatu komoditi yang dipertukarkan sedangkan merek menjelaskan spesifikasi pelanggannya. Memasuki era globalisasi ini produsen dihadapkan pada persaingan untuk meraih dominasi merek. Gencarnya persaingan perusahaan melalui media promosi iklan tersebut minimal mempunyai dua tujuan, pertama adalah mempengaruhi masyarakat untuk melakukan aktivitas beli produk, dan menanamkan kesadaran akan suatu merek. Iklan bahkan merupakan salah satu media untuk memperkenalkan produk baru. Pada dasarnya pesan iklan tersebut erat kaitannya dengan pencitraan merek atau perusahaan.

Salah satu keuntungan dari iklan adalah menguatkan merek (brand). Merek memang bukan sekedar nama, istilah, tanda, ataupun simbol saja, lebih dari itu, merek merupakan sebuah "janji” perusahaan untuk secara konsisten memberikan gambaran, semangat, dan pelayanan pada konsumen. Kalau dulu jika seseorang membutuhkan atau ingin membeli barang, hanya melihat dari sisi core productutility-nya, atau harganya, kini ada lagi faktor-faktor yang menjadi pertimbangan mereka. Salah satunya adalah merek. Di dalam merek ada suatu nilai yang tidak dapat diukur contohnya adalah nilai emosional, nilai keyakinan, gengsi, dan lainlain. Persepsi dapat didefinisikan sebagai proses yang dilakukan individu untuk memilih, mengatur dan menafsirkan stimuli ke dalam gambar yang berarti dan masuk akal mengenai dunia. Persepsi konsumen terhadap suatu merek akan mempengaruhi preferensi terhadap merek-merek yang muncul di hadapannya. Konsumen akan lebih memilih merek yang sesuai dengan kemampuan daya belinya. Selain itu, citra merek (brand image) juga akan menentukan segmen pasar Masalah merek terkait erat dengan persepsi konsumen.

Promosi merupakan salah satu elemen dari marketing mix yang dipakai perusahaan untuk memasarkan produknya. Periklanan merupakan salah satu dari alat promosi yang paling umum digunakan perusahaan untuk menginformasikan, membujuk, dan mengingatkan pembeli sasaran atau masyarakat. Salah satu media promosi dalam bentuk periklanan adalah televisi (TV). Iklim usaha yang semakin menantang, seperti dalam dunia industri telepon selular sekarang membuat manajemen perusahaan, baik yang baru maupun yang lama dapat menjawab tantangan pasar dan memanfaatkan peluang pasar dalam struktur persaingan di masa kini maupun di masa mendatang. Kemampuan perusahaan dalam menangani masalah pemasaran, mencari dan menemukan peluang-peluang pasar akan mempengaruhi kelangsungan hidup perusahaan dalam persaingan. Dalam keadaan ini pihak perusahaan ditantang untuk lebih berperan aktif dalam mendistribusikan dan memperkenalkan produknya agar laku terjual atau setidaknya mempertahankan pangsa pasarnya.

Hal ini berlaku pula di dalam persaingan industri telepon selular atau biasa akrab disapa dengan sebutan ponsel. Inovasi, kualitas, atribut, citra merek, dan tingkat harga produk, menjadi hal-hal yang harus diperhatikan oleh produsen ponsel, agar tidak dikalahkan oleh pesaingnya. Kemajuan teknologi dan ilmu pengetahuan merupakan salah satu faktor utama semakin maraknya pengguna telepon selular. Kemajuan teknologi dalam hal efisiensi biaya dan inovasi sangat mendukung pertumbuhan bisnis 
seluler. Selain itu, adanya perubahan seperti kemajuan di bidang pendidikan, peningkatan pendapatan masyarakat dan semakin majunya teknologi informasi dan komunikasi turut mendorong peningkatan penggunaan telepon selular. Seiring dengan berkembangnya teknologi, masyarakat Indonesia khususnya yang hidup di wilayah perkotaan mulai mengalami perubahan gaya hidup. Bagi mereka, HandPhone (HP) atau ponsel tidak hanya digunakan sebagai alat telepon atau sms saja, tetapi mereka juga sudah memperhatikan fitur-fitur lainnya yang mulai terdapat pada semua jenis dan tipe handphone yang beredar di pasaran. Selain itu, merek handphone sudah menjadi pilihan gaya hidup mereka, merek yang lebih terkenal di kalangan masyarakat Indonesia maka akan lebih diminati daripada merek lainnya yang belum terkenal atau bahkan tidak terkenal sama sekali.

Salah satunya adalah handphone merek Blackberry yang sudah dikenal oleh masyarakat Indonesia pada umumnya. Blackberry sebenarnya adalah perangkat genggam nirkabel yang memiliki kemampuan layanan push e-mail, telepon selular, sms, faksimili Internet, menjelajah Internet, dan berbagai kemampuan nirkabel lainnya. Blackberry kini telah banyak berintegrasi dengan merekmerek handphone (HP), salah satunya adalah Nokia. Blackberry pertama kali diperkenalkan di Indonesia pada pertengahan Desember 2004 oleh operator Indosat dan perusahaan Starhub. Perusahaan Starhub merupakan pengejawantahan dari RIM yang merupakan rekan utama Blackberry. Di Indonesia, Starhub menjadi bagian dari layanan dalam segala hal teknis mengenai instalasi Blackberry melalui operator Indosat. Indosat menyediakan layanan Blackberry Internet Service dan Blackberry Enterprise Server (www.forumsatelit.com). Dalam waktu dekat RI akan menjadi negara dengan pengguna ponsel pintar BlackBerry terbesar di dunia.
Hingga pertengahan 2009 saja, jumlah pengguna ponsel Research in Motion (RIM) itu sudah mencapai angka 300-400 ribu pelanggan. Soal pertumbuhan jangan ditanya, tahun lalu ponsel itu melesat hingga mendekati 500 persen. Meski angka pengguna masih di bawah Amerika Serikat dan Kanada yang rata-rata mencapai satu juta tapi diproyeksikan Indonesia tidak akan perlu waktu lama untuk mengejar ketinggalan itu (www.INILAH.Com).

Peran iklan dalam mempengaruhi penjualan seperti iklan memberikan image tersendiri bagi konsumen yang dikemukakan. Dalam penelitian ini selain dipengaruhi secara langsung oleh iklan, minat beli konsumen juga dipengaruhi oleh merek. Mengingat tidak sedikit biaya yang dikeluarkan oleh perusahaan maka sangatlah penting untuk diketahui sejauh mana iklan berpengaruh bagi peningkatan penjualan produk perusahaan. Target penelitian ini adalah Mahasiswa FE Universitas Islam Lamongan karena mereka memiliki pengetahuan cukup dalam menggunakan produk Blackberry. Berdasarkan uraian di atas maka perlu kiranya diketahui sejauh mana tayangan iklan Blackberry di televisi dan persepsi merek produk Blackberry berpengaruh terhadap minat beli produk Blackberry pada Mahasiswa FE Universitas Islam Lamongan

\section{METODE PENELITIAN \\ Lokasi Penelitian}

Kampus Universitas Islam Lamongan Jalan Veteran no. 53 A Lamongan.

\section{Populasi dan Sampel}

Populasi dalam penelitian ini adalah Mahasiswa FE Universitas Islam Lamongan Prodi Akuntansi Jumlah keseluruhan mahasiswa 150 angkatan 2014-2015.

\section{Sampel}

Sampel adalah sebagian dari populasi. Artinya tidak akan ada sampel jika tidak ada populasi. Dengan menggunakan tingkat 
kesalahan sebesar $10 \%$, besaran sampel yang diambil dari populasi yang berjumlah 150 orang dari kaprodi akuntansi, dan ternyata didapatkan 76 mahasiswa pengguna produk Blackberry.

\section{HASIL DAN PEMBAHASAN}

\section{Analisis Korelasi}

\section{Korelasi Product Moment}

Analisis ini untuk mencari hubungan dan membuktikan hubungan antara variabel $\mathrm{X} 1$ dengan variabel $\mathrm{Y}$ dan antara variabel $\mathrm{X} 2$ dengan variabel $Y$ dimana hasil yang didapat menjelaskan korelasi variabel terpaan iklan televisi produk Blackberry (X1) terhadap variabel minat beli produk Blackberry (Y). Dari tabel di atas diketahui rhitung sebesar0,097 dengan nilai signifikansi sebesar 0,202. Dengan tingkat kepercayaan $99 \%$ atau taraf kesalahan sebesar 0,01 dan jumlah responden sebanyak 76 orang maka didapat rtabel product moment sebesar 0,296. Jika dihitung maka diketahui $\mathrm{r}$ tabel $<\mathrm{r}$ hitung yaitu $0,296>$ -0,097. Tabel di atas menjelaskan korelasi variabel persepsi merek produk Blackberry (X2) terhadap variabel minat beli produk Blackberry (Y). Dari tabel di atas diketahui r hitung sebesar 0,667 dengan nilai signifikansi sebesar 0,000. Dengan tingkat kepercayaan 99\% atau taraf kesalahan sebesar 0,01 dan jumlah responden sebanyak 76 orang maka didapat $r$ tabel product moment sebesar 0,296 Jika dihitung maka diketahui $\mathrm{r}$ tabel $<\mathrm{r}$ hitung yaitu $0,296<0,667$.

Berdasarkan hasil korelasi variabel X1 terhadap Y bahwa tidak terdapat hubungan yang positif antara variabel terpaan iklan televisi dan korelasi variabel X2 terhadap Y dapat ditarik kesimpulan bahwa terdapat hubungan yang positif antara variabel persepsi merek produk Blackberry terhadap minat beli produk Blackberry.

\section{Korelasi Ganda}

Analisis ini untuk mencari hubungan dan membuktikan hubungan antara variabel $\mathrm{X} 1$ dan variabel $\mathrm{X} 2$ dengan variabel $\mathrm{Y}$, di mana hasil yang didapat :

Tabel 4.12

Output Hasil Korelasi X1 dan X2 terhadap Y Model Summary b

\begin{tabular}{|l|r|r|r|r|r|}
\hline Model & \multicolumn{1}{|l|}{$\mathrm{R}$} & R Square & $\begin{array}{l}\text { Adjusted } \\
\text { R Square }\end{array}$ & $\begin{array}{l}\text { Std. Error } \\
\text { of the } \\
\text { Estimate }\end{array}$ & $\begin{array}{l}\text { Durbin- } \\
\text { Watson }\end{array}$ \\
\hline 1 &, $669^{\mathrm{a}}$ &, 447 &, 432 & 9,988 & 1,440 \\
\hline
\end{tabular}

Sumber: Data Primer yang Diolah 2011
a. Predictors: (Constant), X2, X1
b. Dependent Variable: Y

Tabel di atas menjelaskan korelasi variabel terpaan iklan televisi (X1) dan persepsi merek produk Blackberry (X2) terhadap variabel minat beli produk Blackberry (Y). Berdasarkan hasil perhitungan menggunakan program SPSS 13.0 didapat korelasi X1 dan X2 terhadap Y adalah sebesar 0,669. Dari hasil perhitungan tersebut, dapat dikatakan besarnya korelasi ganda (R) harganya lebih besar dibandingkan korelasi individual ryx1 sebesar $-0,097$ dan ryx2 sebesar 0,667. Berdasarkan hasil korelasi variabel X1 terhadap Y dan X2 terhadap Y dapat ditarik kesimpulan bahwa terdapat hubungan yang positif antara variabel terpaan iklan televisi produk Blackberry dan persepsi merek produk Blackberry terhadap minat beli produk Blackberry.

\section{Analisis Regresi \\ Regresi Linier Sederhana}

Pada penelitian ini, dalam menganalisis regresi linier sederhana peneliti menggunakan seri program statistik SPSS versi 13.00. Analisis ini digunakan untuk menganalisis pengaruh variabel terpaan iklan televisi produk Blackberry (X1) terhadap minat beli produk Blackberry (Y). Peneliti juga meng- 
analisis pengaruh variabel persepsi merek produk Blackberry (X2) terhadap Minat Beli produk Blackberry (Y). Perhitungan regresi linier sederhana dengan menggunakan program SPSS didapatkan persamaan :

$\mathrm{Y}=0.914+-0.209 \mathrm{X} 1$

Persamaan regresi di atas, konstanta (Y) adalah sebesar -0.914 dengan signifikansi 0,000 berarti jika tidak ada terpaan iklan televisi produk Blackberry (X1) yang mempengaruhi maka minat beli produk Blackberry tetap sebesar -0.914 satuan.

\section{Pengujian Signifikansi F}

Uji $\mathrm{F}$ ini bertujuan untuk mengetahui apakah variabel terpaan iklan dapat mempengaruhi variabel minat beli produk Blackberry. Pengujian ini dilakukan dengan membandingkan antara nilai Fhitung dengan Ftabel yaitu:

- Jika Fhitung > Ftabel maka menolak H0, sebaliknya

- Jika Fhitung > Ftabel maka menerima Ha

Dari hasil perhitungan dengan menggunakan SPSS diperoleh besarnya Fhitung adalah 0.836 dengan nilai signifikansi 0,364 sedangkan nilai Ftabel dengan taraf signifikan $1 \%$ dan df:n-k-1=76-3-1=72, adalah sebesar 4,92. Dengan demikian Fhitung: $0.836<$ Ftabel: 4.92. Artinya H1 ditolak. Sehingga dapat ditarik kesimpulan variabel terpaan iklan televisi tidak berpengaruh secara signifikan terhadap minat beli produk Blackberry.

Tabel 4.14

Estimasi Regresi Linier Sederhana X1 terhadap Y

Model Summary

\begin{tabular}{|l|r|r|r|r|}
\hline Model & R & RSquare & $\begin{array}{c}\text { Adjusted } \\
\text { RSquare }\end{array}$ & $\begin{array}{c}\text { Std.Errorof } \\
\text { the Estimate }\end{array}$ \\
\hline 1 & $.106^{\mathrm{a}}$ & .011 & - & 13.26677 \\
\hline
\end{tabular}

a. Predictors: (Constant), X1

Sumber: Data Primer yang Diolah 2015
Dari tabel di atas dapat dilihat besarnya persentase semua variabel independen menjelaskan terhadap nilai variabel dependen yang diketahui dari besarnya koefisien determinasi $\left(\mathrm{R}^{2}\right)$. Pada hasil perhitungan dengan menggunakan program SPSS diperoleh besarnya koefisien determinasi ( $\mathrm{R}^{2} / \mathrm{RS}$ quare) adalah 0,011 . Hal ini menyatakan hanya $1.1 \%$ minat beli dapat dijelaskan oleh terpaan iklan produk Blackberry.

\section{Regresi Ganda}

$Y=25,497+-\mathbf{0 , 1 0 6} X 1+\mathbf{0 , 8 0 4} X 2$

Persamaan regresi di atas, konstanta (Y) adalah sebesar 25,497 yang berarti jika tidak ada pengaruh terpaan iklan produk Blackberry televisi (X1) dan persepsi merek produk Blackberry (X2) yang mempengaruhi maka minat beli produk Blackberry pada mahasiswa FE akuntansi Universitas Islam Lamongan sebesar 25,497 satuan.

Penelitian ini bertujuan untuk mengetahui pengaruh terpaan iklan televisi produk Blackberry terhadap minat beli produk Blackberry, pengaruh persepsi merek produk Blackberry terhadap minat beli produk Blackberry, serta pengaruh terpaan iklan televisi dan persepsi merek produk Blackberry terhadap minat beli produk Blackberry. Penelitian ini dilakukan terhadap 76 responden yaitu yang menggunakan produk Blackberry.

Dari hasil penelitian yang telah dilakukan, mengenai hipotesis pertama yakni tidak terdapatnya pengaruh yang positif dan signifikan antara terpaan iklan televisi produk Blackberry terhadap minat beli produk Blackberry, lalu hipotesis kedua adanya pengaruh positif dan signifikan antara persepsi merek produk Blackberry terhadap minat beli produk Blackberry dan hipotesis yang ketiga pengaruh positif dan signifikan antara terpaan iklan televisi dan persepsi merek produk Blackberry terhadap minat beli produk Blackberry pada mahasiswa FE 
akuntansi Universitas Islam Lamongan adalah terbukti. Hal di atas diperkuat oleh hasil pengujian korelasi (hubungan), dimana hasil yang didapat bahwa adanya hubungan yang positif pada persepsi merek produk Blackberry terhadap minat beli produk Blackberry pada mahasiswa FE akuntansi Universitas Islam Lamongan. Pengaruh yang didapat dari analisis regresi ganda diketahui terpaan iklan televisi produk Blackberry dan persepsi merek produk Blackberry $\left(\mathrm{R}^{2}\right)$ sebesar 0,447 yang berarti bahwa terpaan iklan produk Blackberry televisi dan persepsi merek produk Blackberry hanya dapat memberikan pengaruh yang tidak terlalu besar terhadap Minat beli produk Blackberry pada mahasiswa FE akuntansi Universitas Islam Lamongan yaitu sebesar 44,7\%. Dengan demikian terdapat 55,3\% yang menyatakan bahwa Minat beli produk Blackberry mahasiswa FE akuntansi Universitas Islam Lamongan dipengaruhi oleh faktor-faktor lainnya.

\section{PENUTUP \\ Simpulan}

Berdasarkan hasil analisis data dan pembahasan, menunjukkan tidak ada pengaruh positif dan signifikan antara terpaan iklan televisi terhadap minat beli produk Blackberry pada mahasiswa FE akuntansi Universitas Islam Lamongan. Jadi hipotesis yang menyatakan adanya pengaruh positif dan signifikan antara variabel terpaan iklan televisi produk Blackberry terhadap minat beli produk Blackberry pada mahasiswa FE akuntansi Universitas Islam Lamongan tidak dapat diterima. Kesimpulan yang kedua adalah mengenai adanya pengaruh yang positif dan signifikan antara persepsi merek produk Blackberry terhadap minat beli produk Blackberry pada mahasiswa FE akuntansi Universitas Islam Lamongan. Hal ini berarti semakin tinggi persepsi merek maka akan semakin tinggi pula minat beli produk Blackberry. Berlaku sebaliknya semakin rendah skor persepsi merek maka semakin rendah pula minat beli produk Blackberry. Jadi, hipotesis yang menyatakan adanya pengaruh yang positif dan signifikan antara persepsi merek terhadap minat beli produk Blackberry dapat diterima.

Kesimpulan yang ketiga adalah mengenai adanya pengaruh yang positif dan signifikan antara terpaan iklan televisi dan persepsi merek produk Blackberry terhadap minat beli produk Blackberry pada mahasiswa FE akuntansi Universitas Islam Lamongan. Hal ini juga berarti semakin tinggi tingkat terpaan iklan televisi dan persepsi merek maka akan semakin tinggi pula minat beli produk Blackberrynya pada mahasiswa FE akuntansi Universitas Islam Lamongan. Begitu pula sebaliknya semakin rendah tingkat terpaan iklan televisi dan persepsi merek maka semakin rendah pula minat beli produk Blackberry. Jadi, hipotesis yang menyatakan ada pengaruh positif dan signifikan antara terpaan iklan televisi dan persepsi merek produk Blackberry terhadap minat beli produk Blackberry dapat diterima.

Hasil penelitian ini menunjukkan bahwa terpaan iklan televisi dan persepsi merek, dapat mendukung teori S-O-R. Teori S-O-R yang menjelaskan bahwa setiap stimulus (rangsangan) akan menghasilkan respon (tanggapan) secara spontan. Teori SO-R juga menegaskan bahwa media massa memiliki efek-efek bagi pemirsanya. Efekefek tersebut tentunya akan mengacu pada stimulus yang diberikan oleh komunikator hingga terjadinya perubahan sikap ataupun perilaku dari komunikan.

\section{Saran}

Melihat dari pengaruh terpaan iklan televisi produk Blackberry terhadap minat beli produk Blackberry cukup rendah saran yang dapat diberikan:

1. Iklan televisi produk Blackberry 
mengiklankan produknya secara khusus, bukan bekerja sama dengan produk lain seperti pada provider bank yang memberikan cicilan, dan sebagainya. Hal ini penting agar meningkatkan frekuensi penayangannya di media massa supaya semakin dekat dengan calon konsumennya terutama untuk produk-produk yang baru diluncurkan di pasar dalam upaya mempengaruhi minat beli produk tersebut.

2. Bagi peneliti Selanjutnya, disarankan untuk menggunakan metode penelitian yang lain. Disarankan pula untuk peneliti selanjutnya agar dapat melakukan penelitian sejenis lain dengan menambahkan dan mengukur variabel brand loyality dan kepuasan pengguna produk Blackberry yang pada penelitian belum diuji pengaruhnya.

\section{DAFTAR PUSTAKA}

Effendi. 1999. Ilmu Komunikasi: Teori dan Praktek. Bandung: Remaja Rosdakarya.

--------. 1992. Ilmu Komunikasi: Teori dan Praktek. Bandung. Remaja Rosdakarya.

1998. Televisi Siaran dan Praktek. Bandung: CV. Mandar Maju.

Engel, James, Blackwell, Paul, Miniard. 2001. Consumer Behavior. 8.th Edition. Dryden Press. Horcout Brace College Publisher.
Howard. 1994. Buyer Behavior in Marketing Strategy. Prentice Hall. New Jersey.

James. 1995. Perilaku Konsumen, Binarupa Aksara. Jakarta.

Jefkins, Frank. 1996. Periklanan. Erlangga. Jakarta.

Kasali, Rhenald. 1992. Management Periklanan Konsep dan Aplikasinya di Indonesia, Pustaka Utama Grafiti. Jakarta.

Kotler, P. 2000. Manajemen Indonesia (Analisis, Perencanaan, Implementasi, dan Pengendalian) terjemahan A.B. Susanto, buku satu salemba empat Jakarta.

- 2002. Manajemen Pemasaran. Edisi Milenium. Prenhallindo. Jakarta.

---------. 1997. Manajemen PemasaranAnalisis, Perencanaan, Implementasi dan Kontrol, Prenhallindo. Jakarta.

Shimp. 2003. Periklanan Promosi Aspek Tambahan Komunikasi Terpadu. Erlangga. Jakarta.

Slamet. 2001. Teknik Pengambilan Sampel. Pabelan. Surakarta.

Sugiyono. 2005. Statistik untuk Penelitian. IKAPI. Bandung.

Tjiptono, Fandy. 2000. Strategi Pemasaran edisi dua, Andi Offset. Yogyakarta. 